\title{
Liraglutide reverses pronounced insulin-associated weight gain, improves glycaemic control and decreases insulin dose in patients with type 2 diabetes: a 26 week, randomised clinical trial (ELEGANT)
}

\author{
Helena M. de Wit • Gerald M. M. Vervoort • \\ Henry J. Jansen • Wim J. C. de Grauw • \\ Bastiaan E. de Galan • Cees J. Tack
}

Received: 13 April 2014 / Accepted: 4 June 2014 / Published online: 20 June 2014

(C) Springer-Verlag Berlin Heidelberg 2014

\begin{abstract}
Aims/hypothesis The best treatment strategy for a patient with type 2 diabetes who shows pronounced weight gain after the introduction of insulin treatment is unclear. We determined whether addition of a glucagon-like peptide-1 (GLP-1) analogue could reverse pronounced insulin-associated weight gain while maintaining glycaemic control, and compared this with the most practised strategy, continuation and intensification of standard insulin therapy.

Methods In a 26-week, randomised controlled trial (ELEGANT), conducted in the outpatient departments of one academic and one large non-academic teaching hospital in the Netherlands, adult patients with type 2 diabetes with $\geq 4 \%$ weight gain during short-term ( $\leq 16$ months) insulin therapy received either open-label addition of liraglutide $1.8 \mathrm{mg} /$ day $(n=26)$ or continued standard therapy $(n=24)$. A computer-generated random number list was used to allocate treatments. Participants were evaluated every 4-6 weeks for weight, glycaemic control and adverse events. The primary endpoint was between-group weight difference after 26 weeks of treatment (intention to treat).
\end{abstract}

H. M. de Wit $(\varangle) \cdot$ G. M. M. Vervoort · H. J. Jansen •

B. E. de Galan · C. J. Tack

Department of Internal Medicine 463, Section Diabetes,

Radboud University Medical Centre, PO Box 9101,

6500 HB Nijmegen, the Netherlands

e-mail: heleen.dewit@radboudumc.nl

H. J. Jansen

Department of Internal Medicine, Jeroen Bosch Hospital,

's-Hertogenbosch, the Netherlands

W. J. C. de Grauw

Department of Primary and Community Care, Radboud University

Medical Centre, Nijmegen, the Netherlands
Results Of 50 randomised patients (mean age 58 years, BMI $33 \mathrm{~kg} / \mathrm{m}^{2}, \mathrm{HbA}_{1 \mathrm{c}} 7.4 \%$ [57 mmol/mol]), 47 (94\%) completed the study; all patients were analysed. Body weight decreased by $4.5 \mathrm{~kg}$ with liraglutide and increased by $0.9 \mathrm{~kg}$ with standard therapy (mean difference $-5.2 \mathrm{~kg}[95 \% \mathrm{CI}-6.7$, $-3.6 \mathrm{~kg}] ; p<0.001)$. The respective changes in $\mathrm{HbA}_{1 \mathrm{c}}$ were $-0.77 \%(-8.4 \mathrm{mmol} / \mathrm{mol})$ and $+0.01 \%(+0.1 \mathrm{mmol} / \mathrm{mol})($ difference $-0.74 \%[-8.1 \mathrm{mmol} / \mathrm{mol}])([95 \% \mathrm{CI}-1.08 \%$, $-0.41 \%][-11.8,-4.5 \mathrm{mmol} / \mathrm{mol}] ; p<0.001)$; respective changes in insulin dose were $-29 \mathrm{U} /$ day and $+5 \mathrm{U} /$ day (difference $-33 \mathrm{U} /$ day $[95 \% \mathrm{CI}-41,-25 \mathrm{U} /$ day $] ; 0<0.001$ ). In five patients $(19 \%)$, insulin could be completely discontinued. Liraglutide was well tolerated; no severe adverse events or severe hypoglycaemia occurred.

Conclusions/interpretation In patients with pronounced insulin-associated weight gain, addition of liraglutide to their treatment regimen reverses weight, decreases insulin dose and improves glycaemic control, and hence seems a valuable therapeutic option compared with continuation of standard insulin treatment.

Trial registration ClinicalTrials.gov NCT01392898

Funding The study was funded by Novo Nordisk.

Keywords Insulin therapy $\cdot$ Liraglutide $\cdot$ Type 2 diabetes Weight gain

\begin{tabular}{|c|c|}
\hline \multicolumn{2}{|c|}{ Abbreviations } \\
\hline BDI-II & Beckman Depression Inventory II \\
\hline ELEGANT & $\begin{array}{l}\text { Effect of liraglutide on insulin-associated } \\
\text { weight gain in patients with type } 2 \text { diabetes }\end{array}$ \\
\hline GLP-1 & Glucagon-like peptide-1 \\
\hline METS & Metabolic equivalents \\
\hline PAID & Problem Areas in Diabetes Scale \\
\hline RCT & Randomised controlled trial \\
\hline
\end{tabular}




\section{Introduction}

The introduction of insulin therapy is common practice when oral glucose-lowering agents fail to maintain glucose control in patients with type 2 diabetes $[1,2]$. Insulin is safe and efficacious in improving glycaemic control, thereby reducing micro- and possibly macro-vascular complications [3, 4], but it may induce weight gain. This weight gain shows large interindividual differences, with some patients showing no or only minor weight gain and others even losing weight [5]. In a substantial group of patients, however, weight gain is more pronounced $(\geq 4-5 \%)$. This is obviously undesirable in an already overweight population, and it may lead to aversion to the therapy and a further increase in insulin dose, and offset the beneficial effects of insulin [6]. Most insulin-induced weight gain, on average $2-6 \mathrm{~kg}$, occurs within the first 9-12 months of insulin therapy [5, 7, 8]. Hence, a therapy that ameliorates pronounced weight gain when encountered within this time frame would be extremely desirable, but the best treatment strategy for this clinical problem is unclear.

Glucagon-like peptide-1 (GLP-1) analogues stimulate insulin secretion, suppress glucagon release, and reduce food intake, resulting in improved glycaemic control and weight loss in type 2 diabetes [9-15]. Addition of GLP-1 analogues to insulin therapy may thus be beneficial in reversing pronounced insulin-induced weight gain. However, GLP-1 analogues are expensive, have gastrointestinal side effects, and lack long-term safety and efficacy data, which renders it important to select those patients that are most likely to benefit from this therapy. Previous studies on the combination of GLP-1 analogues and insulin all focused on glycaemic benefit, with some reporting additional weight loss and others stable body weight [16-31]. Furthermore, most studies are either placebo controlled or observational and do not compare clinically relevant treatment strategies. We hypothesised that addition of a GLP-1 analogue to insulin therapy may reverse pronounced insulin-induced weight gain while maintaining glycaemic control, in comparison with the standard approach, i.e. continuation and intensification of insulin. This hypothesis was tested by the Effect of Liraglutide on Insulin-associated Weight Gain in Patients with Type 2 Diabetes (ELEGANT) trial.

\section{Methods}

Study design and participants This 26-week open-label, randomised, controlled clinical trial was conducted in the Radboud University Medical Centre and one affiliated large non-academic teaching hospital (Jeroen Bosch Hospital, 's-Hertogenbosch, the Netherlands) between February 2012 and October 2013. The trial was approved by the institutional review board (IRB) of the Radboud University Medical
Centre and conducted according to Good Clinical Practices and the Declaration of Helsinki. All participants provided written informed consent and received reimbursement of travel costs.

Potentially eligible individuals with type 2 diabetes were selected from the outpatient departments of the two participating hospitals, recruited by advertisement, or enrolled by their diabetes nurse or general practitioner. They were men or women aged 18-75 years, with a BMI of $\geq 25 \mathrm{~kg} / \mathrm{m}^{2}$ and $\mathrm{HbA}_{1 \mathrm{c}}$ of $\geq 6.5$ and $\leq 8.5 \%$ ( $\geq 48$ and $\left.\leq 69 \mathrm{mmol} / \mathrm{mol}\right)$, who had recently started insulin therapy ( $\geq 3$ and $\leq 16$ months), with concomitant documented weight gain of $\geq 4 \%$ body weight since initiation of insulin treatment. All types and regimens of insulin were allowed. Exclusion criteria were recurrent hypoglycaemia, diabetic gastroparesis, use of oral glucoselowering agents or drugs known to interfere with blood glucose levels other than sulfonylurea or metformin, recent start of diuretics, heart failure (left ventricular ejection fraction of $<30 \%$ ), inflammatory bowel disease, a recent history of pancreatitis, uncontrolled thyroid disease, liver enzymes $\geq 3.0$ times upper normal limit, plasma creatinine $>130 \mu \mathrm{mol} / \mathrm{l}$, and pregnancy.

The initial protocol was amended twice: the duration of insulin treatment was changed from $\leq 12$ to $\leq 16$ months because it turned out that weight change was notified later than expected resulting in delayed inclusion in the trial, and the number of participants was decreased as the weight-reducing effect of liraglutide was greater than anticipated. Both amendments were submitted to and approved by the IRB.

Randomisation and study procedures Participants who met the screening criteria were randomised (1:1), using a computer-generated random number list, to open-label treatment with liraglutide (Novo Nordisk, Bagsvaerd, Denmark) $1.8 \mathrm{mg}$ once daily or standard therapy (continuation and intensification of insulin therapy without liraglutide). Participants were randomised in blocks of four according to body weight $(\leq 100 \mathrm{~kg}$ or $>100 \mathrm{~kg})$.

After enrolment, all participants continued their usual diet and exercise regimens as well as insulin therapy and oral glucose-lowering agents (sulfonylurea and metformin). None of the patients received a dietary consultation; also, no additional nutritional recommendations were made. In patients randomised to liraglutide, total insulin dose was decreased by $20 \%$ to avoid hypoglycaemia. Liraglutide was injected subcutaneously into the thigh or abdomen and administered at any (consistent) time of day. It was initiated in $0.6 \mathrm{mg} /$ day weekly increments to a final $1.8 \mathrm{mg} /$ day dose. When adverse events occurred, participants were allowed to return to the $1.2 \mathrm{mg}$ dose. For safety reasons, participants were instructed to perform daily self-measured capillary blood glucose profiles during the first 3 weeks after the start of liraglutide, and insulin dose was adjusted weekly by telephone consultation. 
For both treatment groups, follow-up visits were scheduled at 4, 8, 12, 16, 20 and 26 weeks. During every visit, participants were asked to report adverse events, body weight was measured on a calibrated scale (with the participant in light underwear), blood pressure was measured, and insulin dose was adjusted using a specific algorithm (adapted from the Wolverhampton protocol) [24]. According to this protocol, insulin dose was adjusted with -2 to $+6 \mathrm{U}$ per injection, aiming at fasting glucose levels of $4.0-6.5 \mathrm{mmol} / \mathrm{l}$, and premeal (or postprandial) values of $\leq 8.0 \mathrm{mmol} / \mathrm{l}$. $\mathrm{HbA}_{1 \mathrm{c}}$ was determined every 8 weeks using an HPLC method. At baseline and end of follow-up, blood was drawn for determination of fasting blood glucose, $\mathrm{HbA}_{1 \mathrm{c}}$, full blood cell count, thyroid function, liver enzymes and serum creatinine. Measurements of all variables were performed in the national accredited clinical laboratory units of the two participating hospitals, according to standard procedures. Also, at baseline and at 26 weeks, quality-of-life questionnaires on diabetes-related distress (Problem Areas in Diabetes Scale [PAID]) [32] and depression (Beckman Depression Inventory II [BDI-II]) [33] were administered, and waist and hip circumference were measured. Physical activity including energy expenditure and average metabolic equivalent (METS; 1 MET equals consumption of $4 \mathrm{~kJ}$ [1 kcal] $/ \mathrm{kg}$ of body weight per hour) was measured quantitatively at baseline and at 26 weeks via a portable armband (HealthWear Bodymedia, Pittsburgh, Pennsylvania, USA) [34] for four consecutive days. The armband was worn around the upper right arm and was removed only for showering and bathing purposes. It had to be worn at least $90 \%$ of time to be included for analysis.

Outcome measures The primary efficacy endpoint was the change in body weight between the two treatment groups from baseline to week 26. Secondary endpoints included change in $\mathrm{HbA}_{1 \mathrm{c}}$, insulin dose, physical activity and quality of life, and number of patients discontinuing insulin. Safety assessments included adverse events and number and severity of hypoglycaemic episodes. Hypoglycaemia $(<3.9 \mathrm{mmol} / \mathrm{l})$ was graded asymptomatic or mild (grade 1), moderate (requiring additional oral carbohydrate; grade 2) and severe (requiring third-party assistance, irrespective of glucose levels; grade 3).

Statistical analysis and power calculation All statistical analyses were performed according to intention-to-treat, using IBM SPSS version 20.0 (Chicago, Illinois, USA). $p<0.05$ was considered significant. Descriptive characteristics are expressed as mean $\pm \mathrm{SD}$; results are expressed as mean \pm SEM, unless otherwise indicated.

With 50 randomised participants and a dropout rate of $<20 \%$, 21 participants per treatment arm would provide an $80 \%$ power to detect a clinically relevant treatment difference of $4 \%(4.0 \mathrm{~kg})$ in the absolute change in body weight from baseline to week 26 . This assumed an SD of $4.6 \mathrm{~kg}$ with a two-sided 5\% significance level.
A linear mixed model for repeated measures was used to estimate the effect of treatment on weight, $\mathrm{HbA}_{1 \mathrm{c}}$ and insulin dose at multiple time points with fixed effects for treatment, visit, treatment-by-visit interaction, baseline weight stratum, baseline of the variable analysed and centre. Treatment differences are summarised by maximum likelihood means and 95\% CIs from the mixed model. Missing values were not imputed. Independent two-tailed $t$ tests (or Mann-Whitney $U$ tests for non-parametric data) were performed to assess between-group differences in all other secondary endpoints, baseline continuous variables and hypoglycaemia rates. The Fisher exact test or $\chi^{2}$ test was used as appropriate for analysis of between-group differences in categorical variables. Multiple linear regression analysis was used to assess factors at baseline and at follow-up associated with weight loss after 26 weeks of liraglutide treatment. Variables included in linear regression analysis were selected using the backward stepwise method. A variable stayed in the model if it had a $p$ value of $<0.05$.

\section{Results}

A total of 64 potentially eligible participants underwent screening. Fifty were randomised and assigned to liraglutide or standard therapy (Fig. 1). Three participants $(6 \%)$ dropped out prematurely: two in the standard therapy group withdrew consent after 1 and 10 weeks of follow-up, respectively; one patient randomised to liraglutide stopped after 4 weeks of treatment because of exaggeration of acne, which could not be objectified by the research staff and was judged to be unrelated to study medication. Baseline characteristics of the two groups were similar and are presented in Table 1. Participants in this trial were generally middle-aged and overweight (mean BMI of $33 \mathrm{~kg} / \mathrm{m}^{2}$ ), with fair glucose regulation (mean $\mathrm{HbA}_{1 \mathrm{c}} 7.4 \%$ [57 mmol/mol] $)$, and had gained on average $7.1 \mathrm{~kg}$ while on insulin treatment. Most were white, except for one who was of Asian origin.

Change in body weight and anthropometric variables Body weight had decreased by $4.5 \pm 0.5 \mathrm{~kg}$ after 26 weeks of treatment with liraglutide and increased by $0.9 \pm 0.6 \mathrm{~kg}$ with standard therapy (maximum likelihood mean difference $-5.2 \mathrm{~kg}$ [95\% CI $-6.7,-3.6 \mathrm{~kg}] ; p<0.001$ ) (Fig. 2), corresponding to $-4.8 \pm 0.5 \mathrm{vs}+1.0 \pm 0.5$ percentage change in body weight, and between-group difference in BMI of $-1.7 \pm 0.3 \mathrm{~kg} / \mathrm{m}^{2}$. Patients in the liraglutide group lost on average $81.3 \%$ of insulinassociated weight gain; 10 participants $(38.5 \%)$ even showed complete reversal of weight gain, compared with none of the patients in the standard therapy group. Baseline factors associated with weight loss were being female, high insulin dose and lower BMI, while, during follow-up, the decrease in $\mathrm{HbA}_{1 \mathrm{c}}$ was closely related to weight loss (data not shown). 
Fig. 1 Enrolment and outcomes

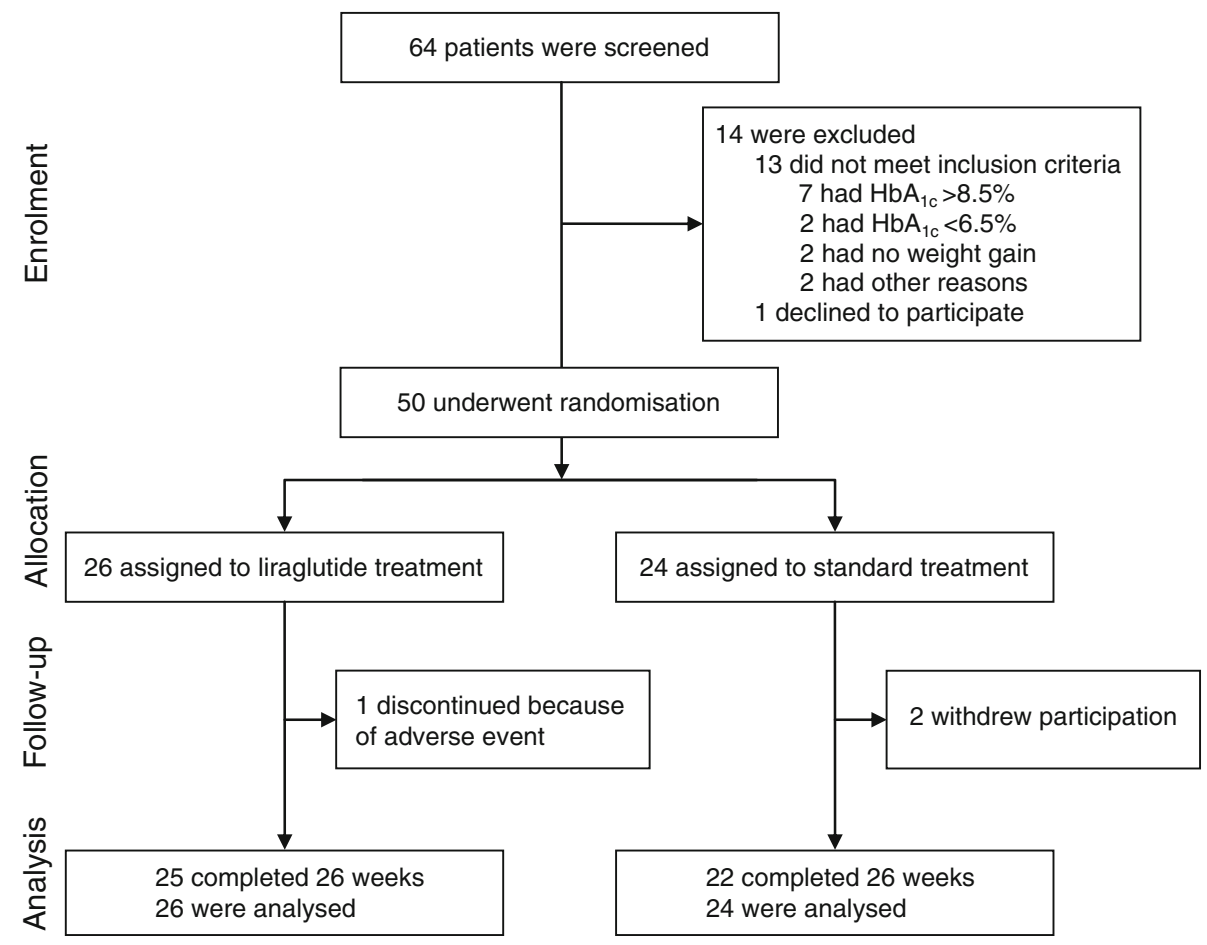

After 26 weeks, waist and hip circumference decreased by 2.1 and $1.5 \mathrm{~cm}$, respectively, in the liraglutide group and increased by 2.7 and $3.0 \mathrm{~cm}$, respectively, in the standard therapy group $(p<0.05$ for both comparisons) (Table 2).

Secondary efficacy measures Glycaemic control, reflected by the change in $\mathrm{HbA}_{1 \mathrm{c}}$, decreased by $0.77 \pm 0.11 \%$ (8.4 \pm $1.2 \mathrm{mmol} / \mathrm{mol})$ with liraglutide and increased by $0.01 \pm$ $0.12 \%(0.1 \pm 1.3 \mathrm{mmol} / \mathrm{mol})$ with standard therapy (maximum likelihood mean difference $-0.74 \%[-8.1 \mathrm{mmol} / \mathrm{mol}]$ ([95\% CI $-1.08 \%,-0.41 \%][-11.8,-4.5 \mathrm{mmol} / \mathrm{mol}]) ; p<0.001)$ (Fig. 2). Nineteen (73\%) participants in the liraglutide group and seven $(29 \%)$ in the standard therapy group reached an $\mathrm{HbA}_{1 \mathrm{c}}$ value of $7.0 \%$ (53 mmol/mol) or less $(p=0.004)$. The insulin dose was reduced by $29 \pm 3 \mathrm{U} /$ day $(-55.7 \pm 4.1 \%)$ with liraglutide and increased by $5 \pm 3 \mathrm{U} /$ day $(+11.8 \pm 4.4 \%)$ with insulin (maximum likelihood mean difference $-33 \mathrm{U} /$ day [95\% CI $-41,-25 \mathrm{U} /$ day]; $p<0.001$ ) (Fig. 2), corresponding to $-0.29 \pm 0.03 \mathrm{U} / \mathrm{kg}$ and $+0.04 \pm 0.03 \mathrm{U} / \mathrm{kg}$, respectively. Five participants (19\%) in the liraglutide group were able to discontinue insulin therapy. This subgroup had a baseline BMI of $29 \pm 5 \mathrm{~kg} / \mathrm{m}^{2}$, weight reduction after 26 weeks of $-3.8 \pm 0.8 \mathrm{~kg}$, an $\mathrm{HbA}_{1 \mathrm{c}}$ reduction of $-0.4 \pm 0.3 \%(-4.4 \pm 3.3 \mathrm{mmol} / \mathrm{mol})$, and a relatively low insulin dose at baseline (four of them were treated with 20-24 U/day, one was treated with $84 \mathrm{U} /$ day). No statistically significant changes in blood pressure and heart rate occurred in either group (Table 2).

Safety Liraglutide-treated patients often reported adverse gastrointestinal events, mostly decreased appetite (92.3\%), dyspepsia $(76.9 \%)$, constipation $(53.8 \%)$ and nausea (42.3\%) (Table 3). Although common, adverse events were mostly mild-to-moderate in severity and typically resolved after the first 4-8 weeks; at 26 weeks, only nine $(35 \%)$ liraglutide-treated patients reported any gastrointestinal complaints, the majority of mild severity. In two participants, diarrhoea resolved after metformin was discontinued. No serious adverse events were reported. No change in liver or renal function occurred. Of the 26 participants treated with liraglutide, three $(11.5 \%)$ were on a dose of $1.2 \mathrm{mg}$. The overall rate of hypoglycaemia was similar across treatment groups (Table 3). Minor (grade 1,2) hypoglycaemia rates were 3.85 and 2.70 events per participant per year for the liraglutide and standard therapy group, respectively. No major (grade 3) hypoglycaemic events occurred.

Physical activity levels and quality of life There were no changes in average total energy expenditure and physical activity (as reflected by steps per day and average METS per day) or quality of life (as reflected by the BDI-II and PAID questionnaires), neither among nor between the two groups during treatment (Table 2).

\section{Discussion}

Our study shows that addition of the GLP-1 analogue, liraglutide, to patients with pronounced insulin-induced weight gain results in a substantial reversal of weight, while 
Table 1 Baseline characteristics

\begin{tabular}{|c|c|c|}
\hline Characteristic & $\begin{array}{l}\text { Liraglutide } \\
(n=26)\end{array}$ & $\begin{array}{l}\text { Standard therapy } \\
(n=24)\end{array}$ \\
\hline Age, years & $57 \pm 10$ & $59 \pm 8$ \\
\hline Sex, male:female & $16: 10$ & $15: 9$ \\
\hline Diabetes duration, years & $8.3 \pm 5.9$ & $7.6 \pm 6.2$ \\
\hline Insulin treatment duration, months & $11 \pm 4$ & $10 \pm 4$ \\
\hline Body weight, kg & $102.3 \pm 20.1$ & $97.7 \pm 18.5$ \\
\hline BMI, $\mathrm{kg} / \mathrm{m}^{2}$ & $34 \pm 7$ & $32 \pm 5$ \\
\hline \multicolumn{3}{|l|}{ Insulin-associated weight gain } \\
\hline $\mathrm{kg}$ & $6.7 \pm 3.8$ & $7.5 \pm 4.2$ \\
\hline$\%$ & $6.8 \pm 2.8$ & $8.2 \pm 3.8$ \\
\hline \multicolumn{3}{|l|}{$\mathrm{HbA}_{1 \mathrm{c}}$} \\
\hline$\%$ & $7.2 \pm 0.6$ & $7.5 \pm 0.7$ \\
\hline $\mathrm{mmol} / \mathrm{mol}$ & $56 \pm 7$ & $59 \pm 7$ \\
\hline Waist circumference, $\mathrm{cm}$ & $110 \pm 13$ & $107 \pm 15$ \\
\hline Hip circumference, $\mathrm{cm}$ & $106 \pm 11$ & $104 \pm 12$ \\
\hline \multicolumn{3}{|l|}{ Oral glucose-lowering medication, $n(\%)$} \\
\hline None & $3(11.5)$ & $3(12.5)$ \\
\hline Metformin only & $13(50)$ & $12(50)$ \\
\hline Sulfonylurea only & $2(7.7)$ & $2(8.3)$ \\
\hline Sulfonylurea and metformin & $8(30.8)$ & $7(29.2)$ \\
\hline \multicolumn{3}{|l|}{ Insulin dose } \\
\hline $\mathrm{U} /$ day & $54 \pm 34$ & $50 \pm 33$ \\
\hline $\mathrm{U} \mathrm{kg}^{-1}$ day $^{-1}$ & $0.51 \pm 0.30$ & $0.50 \pm 0.29$ \\
\hline \multicolumn{3}{|l|}{ Insulin regimen, $n(\%)$} \\
\hline Basal insulin (only) & $14(53.8)$ & $13(54.2)$ \\
\hline Basal bolus & $8(30.8)$ & $8(33.3)$ \\
\hline Biphasic insulin & $4(15.4)$ & $2(8.3)$ \\
\hline Pump therapy & 0 & $1(4.2)$ \\
\hline \multicolumn{3}{|l|}{ Concomitant medication, $n(\%)$} \\
\hline Antihypertensive & $17(65.4)$ & $14(58.3)$ \\
\hline Cholesterol-lowering & $21(80.8)$ & $19(79.2)$ \\
\hline Current smoker, $n(\%)$ & $1(3.8)$ & $4(16.7)$ \\
\hline Alcohol consumption $\geq 1 \mathrm{U} /$ day, $n(\%)$ & $5(19.2)$ & $7(29.2)$ \\
\hline
\end{tabular}

Data are expressed as mean \pm SD unless otherwise indicated

$p>0.05$ for all between-group differences

glucose control is maintained or even improved. These findings suggest that adding liraglutide to insulin treatment is a valuable treatment strategy for these patients, for whom other methods to lose weight are difficult to implement, whereas continuation and intensification of insulin therapy leads to further weight gain.

Some previous studies, mostly observational, have investigated the effect of adding GLP-1 analogues to existing insulin treatment in patients with type 2 diabetes [16-31]. Our study differs from previous randomised controlled trials (RCTs) in that this is the first RCT where liraglutide was added to reverse weight gain in fairly well controlled patients, while
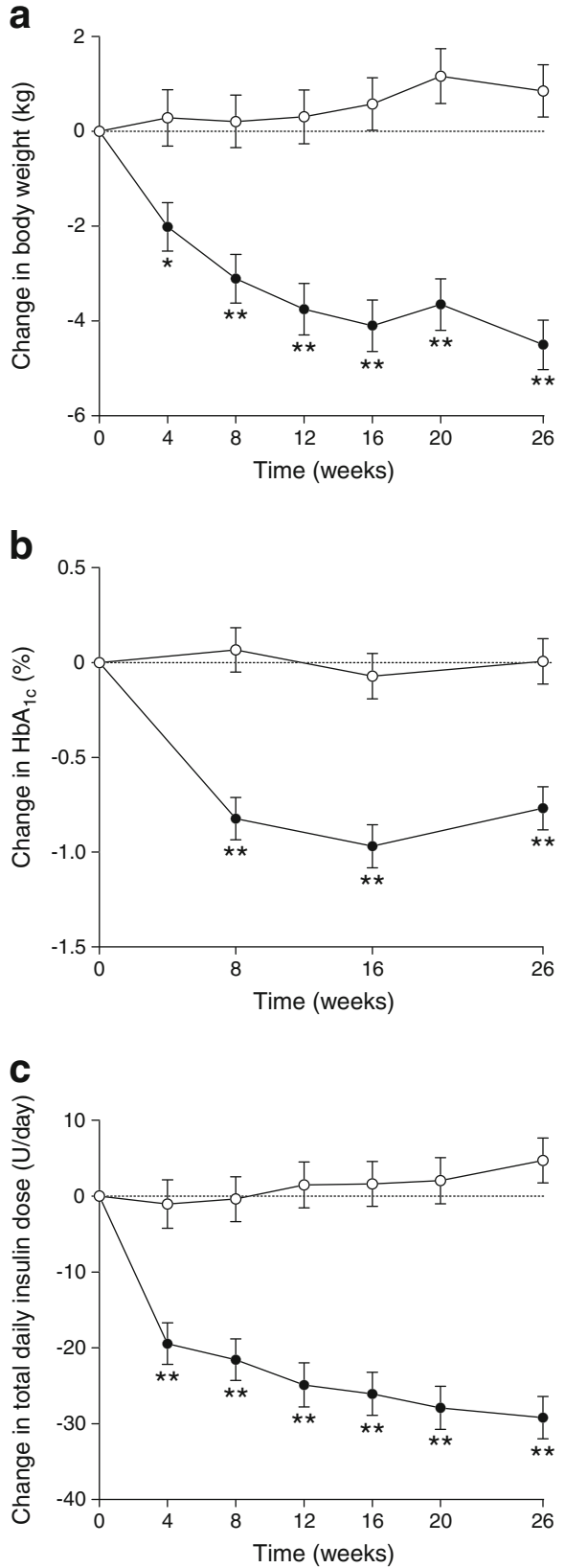

Fig. 2 Maximum likelihood mean \pm SEM changes in (a) weight, (b) $\mathrm{HbA}_{1 \mathrm{c}}$ and (c) insulin dose, from baseline to week 26 for the liraglutideadded group (black circles) compared with the group continuing standard insulin therapy (white circles). ${ }^{*} p<0.05,{ }^{* *} p<0.001$ compared with standard therapy at the same time point. To convert values for $\mathrm{HbA}_{1 \mathrm{c}}$ in DCCT \% into $\mathrm{mmol} / \mathrm{mol}$, subtract 2.15 and multiply by 10.929

all other trials added GLP-1 analogues to improve glycaemic control, and reported results on body weight as secondary outcomes, showing mixed results [16, 17, 19, 23, 25-27]. Furthermore, we compared two clinically relevant treatment strategies for handling insulin-induced weight gain, a therapeutic challenge often faced by clinicians, which no RCT has ever addressed. The $5.4 \mathrm{~kg}$ weight difference we found between addition of liraglutide and continuation of insulin is far greater than reported earlier in RCTs on the combination of 
Table 2 Changes from baseline in secondary outcome variables

\begin{tabular}{llll}
\hline Variable & $\begin{array}{l}\text { Liraglutide } \\
(n=26)\end{array}$ & $\begin{array}{l}\text { Standard } \\
\text { therapy }(n=24)\end{array}$ & $p$ value \\
\hline
\end{tabular}

Cardiovascular

Systolic blood pressure, $\mathrm{mmHg}$

$\begin{array}{llll}\text { Baseline } & 137 \pm 16 & 141 \pm 15 & \\ \text { Change from baseline } & -7 \pm 2 & -3 \pm 3 & 0.25 \\ \text { to week 26 } & & & \end{array}$

Diastolic blood pressure, $\mathrm{mmHg}$

$\begin{array}{lll}\text { Baseline } & 81 \pm 6 & 82 \pm 8 \\ \text { Change from baseline } & -2 \pm 1 & -3 \pm 2\end{array}$

Change from baseline $-2 \pm 1$ to week 26

Heart rate, beats/min

Baseline $\quad 74 \pm 10 \quad 72 \pm$

Change from baseline $\quad-3 \pm 2 \quad-2 \pm 3$

to week 26

Anthropometric

Change in BMI, $\mathrm{kg} / \mathrm{m}^{2}$

Change in waist

circumference, $\mathrm{cm}$

Change in hip circumference, $\mathrm{cm}$

$-1.4 \pm 0.3$

$0.3 \pm 0.2$

$-2.1 \pm 1.3$

$2.7 \pm 1.2$

$-1.5 \pm 1.4 \quad 3.0 \pm 1.4$

0.80

2

Quality of life scores ${ }^{\mathrm{a}}$

PAID

$\begin{array}{lll}\begin{array}{l}\text { Baseline } \\ \text { Change from baseline } \\ \text { to week 26 }\end{array} & -5 \pm 2 & 14 \pm 11 \\ \begin{array}{l}\text { BDI-II } \\ \text { Baseline }\end{array} & -4 \pm 2 \\ \text { Change from baseline } & -1 \pm 2 & 0 \pm 8\end{array}$

to week 26

Physical activity

TEE, $\mathrm{kJ} /$ day

\begin{tabular}{|c|c|c|c|}
\hline Baseline & $8.6 \pm 2.0$ & $8.8 \pm 1.4$ & \\
\hline $\begin{array}{l}\text { Change from baseline } \\
\text { to week } 26\end{array}$ & $0.01 \pm 0.34$ & $0.03 \pm 0.20$ & 0.54 \\
\hline \multicolumn{4}{|l|}{ Steps per day } \\
\hline Baseline & $6,346 \pm 2,914$ & $7,219 \pm 3,103$ & \\
\hline $\begin{array}{l}\text { Change from baseline } \\
\text { to week } 26 \\
\text { METS per day, } \mathrm{kJ} \mathrm{kg}^{-1} \mathrm{~h}^{-1}\end{array}$ & $275 \pm 621$ & $-141 \pm 408$ & 0.74 \\
\hline Baseline & $5.5 \pm 1.3$ & $5.9 \pm 1.1$ & \\
\hline $\begin{array}{l}\text { Change from baseline } \\
\text { to week } 26\end{array}$ & $0.23 \pm 0.19$ & $-0.09 \pm 0.15$ & 0.20 \\
\hline
\end{tabular}

Data are expressed as mean \pm SD for baseline (descriptive) characteristics; changes from baseline are expressed as mean \pm SEM

${ }^{a}$ Scores on quality of life, as assessed by the patient, with higher scores indicating a poorer quality of life

METS, metabolic equivalents (1 MET equals consumption of $4 \mathrm{~kJ}$ [1 kcal] $/ \mathrm{kg}$ of body weight per hour); TEE, total energy expenditure

GLP-1 analogues and insulin, where average weight loss after 26 weeks did not exceed $2.8 \mathrm{~kg}$ [17, 23, 25-27]. Only one recently published trial, by Lane and colleagues, found a $5.3 \mathrm{~kg}$ weight loss after 24 weeks in 21 extremely obese
Table 3 Number of patients reporting adverse events

\begin{tabular}{|c|c|c|c|}
\hline Event & $\begin{array}{l}\text { Liraglutide } \\
(n=26)\end{array}$ & $\begin{array}{l}\text { Standard therapy } \\
(n=24)\end{array}$ & $p$ value \\
\hline Any severe adverse event & $8(30.8)$ & $2(8.3)$ & 0.08 \\
\hline Decreased appetite & $24(92.3)$ & $2(8.3)$ & $<0.001$ \\
\hline Dyspepsia & $20(76.9)$ & $1(4.2)$ & $<0.001$ \\
\hline Constipation & $14(53.8)$ & $2(8.3)$ & 0.001 \\
\hline Nausea & $11(42.3)$ & $3(12.5)$ & 0.03 \\
\hline Diarrhoea & $10(38.5)$ & $6(25)$ & 0.37 \\
\hline Headache & $10(38.5)$ & $6(25)$ & 0.37 \\
\hline Vertigo & $10(38.5)$ & $4(16.7)$ & 0.12 \\
\hline Abdominal pain & $9(34.6)$ & $1(4.2)$ & 0.01 \\
\hline Rhinopharyngitis & $8(30.8)$ & $7(29.2)$ & $>0.99$ \\
\hline Vomiting & $6(23.1)$ & $1(4.2)$ & 0.10 \\
\hline \multicolumn{4}{|l|}{ Hypoglycaemia } \\
\hline Grade 1 & $13(50)$ & $8(33.3)$ & 0.27 \\
\hline Episodes patient $^{-1}$ year $^{-1}$ & $3.23 \pm 1.09$ & $2.52 \pm 1.29$ & 0.21 \\
\hline Grade 2 & $4(15.4)$ & $2(8.3)$ & 0.67 \\
\hline Episodes patient ${ }^{-1}$ year $^{-1}$ & $0.62 \pm 0.31$ & $0.17 \pm 0.17$ & 0.21 \\
\hline Grade 1,2 & $15(57.7)$ & $8(33.3)$ & 0.10 \\
\hline Episodes patient $^{-1}$ year $^{-1}$ & $3.85 \pm 1.17$ & $2.70 \pm 1.30$ & 0.10 \\
\hline
\end{tabular}

Counts are displayed as number (\%) of patients reporting an adverse event or mean \pm SEM

Only adverse events reported $>5 \%$ are depicted

(BMI $39.6 \mathrm{~kg} / \mathrm{m}^{2}$ ) patients with insulin-resistant type 2 diabetes [19]. The larger weight loss observed in the present study may be explained first by the fact that it was not designed with the intention to improve glycaemic control, as improvement in glycaemic control is usually associated with weight gain [5, 8]. Second, liraglutide-induced insulin dose reductions were greater in our study than in others [17, 19, 23, 25-27], and the decrease in insulin dose was also a predictor of weight loss. Finally, patients in our study were selected for pronounced insulin-associated weight gain. Interestingly, the amount of insulin-induced weight gain was not significantly related to the amount of liraglutide-induced weight loss. In contrast with the registration trials [10-14], weight loss with liraglutide was inversely related to BMI, with the greatest weight loss occurring in patients with a lower rather than a higher BMI.

Although not intended, $\mathrm{HbA}_{1 \mathrm{c}}$ fell by $0.77 \%(8.4 \mathrm{mmol} / \mathrm{mol})$ after 26 weeks, which is a known effect of liraglutide and within the range of reductions observed in most previous RCTs on insulin-GLP-1 analogue combinations [19, 23, 25-27]. The two treatment groups showed numerical differences in smoking and drinking habits, which may be relevant, as smoking is known to influence insulin resistance. However, these differences were not statistically significantly different, and, with linear regression analyses, we found no relationship between smoking and drinking habits and $\mathrm{HbA}_{1 \mathrm{c}}$ reduction and weight loss. In our study, one in five patients could completely discontinue insulin. As 
glycaemic control in most patients improved beyond target, one may speculate that more aggressive down-titration of insulin might have resulted in even more weight loss and a larger proportion of patients being able to discontinue insulin treatment.

As expected, adverse gastrointestinal events associated with liraglutide occurred in the first 4-8 weeks of treatment and mostly concerned loss of appetite, dyspepsia and constipation rather than vomiting and diarrhoea, as often reported [35]. Neither the presence nor the severity of these events was related to the magnitude of weight loss or $\mathrm{HbA}_{1 \mathrm{c}}$ reduction. The withdrawal rate due to adverse events was much lower in our study than in others [17, 24, 27], possibly because we monitored patients every 4-6 weeks and allowed them to remain on a lower liraglutide dose when needed. This could also have prevented a higher rate of hypoglycaemia in the liraglutide-treated group, the absence of which has been described previously [17, 19, 22, 23, 25]. The use of sulfonylurea was similar in the two groups, and sulfonylurea did not explain changes in body weight or occurrence of hypoglycaemia in linear regression analysis.

Our study has limitations. First, only patients with pronounced insulin-induced weight gain in the first 16 months of insulin therapy were included and therefore we cannot vouch for the efficacy of liraglutide in patients with less pronounced weight gain or weight gain on long-term insulin treatment. We defined $4 \%$ weight gain as pronounced, as this reflects the upper $50 \%$ of insulin-associated weight gain and a minimal weight reduction of $3-5 \%$ in obese participants is already associated with a clinically relevant reduction in health risk [6, 36, 37]. Second, as our study duration was 26 weeks, it cannot determine whether the effects of addition of liraglutide to insulin are sustained after this time period. Our study included only 50 patients, and, although intended, it was not placebo controlled, which could be viewed as a limitation. The open study design may have caused unintended differences in compliance with dietary advice between the treatment groups, although the similar physical activity scores suggest such an effect to be minimal at the most. Next, the three additional telephone consultations in the first 4 study weeks for liraglutide-treated patients may have added to the effect of the liraglutide intervention. These consultations were appointed for safety reasons only and were not scheduled in the group receiving standard therapy, because they were less likely to experience hypoglycaemia and treatment-related adverse events. Furthermore, as two different treatment strategies were compared, these consultations are not part of a regular insulin-treatment strategy. Nevertheless, the comparison of two different, clinically relevant, treatment strategies is just the strength of the study. Currently, the most practised approach for patients with insulin-associated weight gain is continuation and intensification of insulin treatment. A further strength of this investigator-initiated study is that it reflects real-world clinical practice and permitted various insulin regimens and oral glucose-lowering agents.
In current clinical practice, insulin therapy is still the cornerstone of type 2 diabetes therapy. Most patients will reach a good or at least fair $\mathrm{HbA}_{1 \mathrm{c}}$ level with insulin but, in some patients, at the expense of significant weight gain. According to clinical practice guidelines, addition of a GLP-1 analogue is not indicated in this situation [1]. We show, however, that the addition of liraglutide in patients with pronounced weight gain was effective in reversing weight gain, allowed one in five patients to discontinue insulin treatment completely, and reduced insulin need in most others, while glycaemic control further improved. Nevertheless, not all patients responded to the therapy. In fact, the effects of the therapy were clear within 12-16 weeks and indicative already after 8 weeks. Hence, a 3 month trial period may be a suitable approach to test the weight and $\mathrm{HbA}_{1 \mathrm{c}}$-reducing potential of liraglutide in individual patients with pronounced insulin-associated weight gain. In those that show no response within this time frame, the treatment could be discontinued. Further studies are needed to assess whether such an approach within the modern concept of personalised, patient-centred healthcare is cost-effective. Our trial contributes to future debates on these matters.

Acknowledgements We wish to thank the study participants. We also thank P. van de Ven, S. Hendriks, L. Zimmerman (diabetes nurses at Radboud University Medical Centre, Nijmegen, the Netherlands) and A. Ek and J. Balk (diabetes nurses at Jeroen Bosch Hospital, 's-Hertogenbosch, the Netherlands) for conducting some of the outpatient visits.

Funding This is an investigator-initiated trial, which was funded by Novo Nordisk, Alphen aan den Rijn, the Netherlands. Novo Nordisk also provided the medication. Novo Nordisk was not involved in the design of the study, the collection, management, analysis and interpretation of the data, the writing of the report, or the decision to submit the paper for publication.

Duality of interest CT received research grants, served as a consultant for, or gave lectures organised by, Merck, Janssen, AstraZeneca, Novartis and Novo Nordisk. All other authors declare that there is no duality of interest associated with their contribution to this manuscript.

Contribution statement GMMV, HJJ, BEdG and CJT designed the study. HMdW, GMMV, HJJ and WJCdG acquired data. HMdW and GMMV analysed and interpreted the data. HMdW, CJT, GMMV and BEdG drafted the manuscript. All authors revised the manuscript for critical intellectual content and approved the final version of the manuscript. CJT obtained funding. CJT is the guarantor of this work and, as such, had full access to all of the data in the study and takes responsibility for the integrity of the data and accuracy of the data analysis.

\section{References}

1. Inzucchi SE, Bergenstal RM, Buse JB et al (2012) Management of hyperglycaemia in type 2 diabetes: a patient-centered approach. Position statement of the American Diabetes Association (ADA) and the European Association for the Study of Diabetes (EASD). Diabetologia 55:1577-1596 
2. Riddle MC (2004) Timely initiation of basal insulin. Am J Med 116(Suppl 3A):3S-9S

3. UK Prospective Diabetes Study (UKPDS) Group (1998) Intensive blood-glucose control with sulphonylureas or insulin compared with conventional treatment and risk of complications in patients with type 2 diabetes (UKPDS 33). Lancet 352:837-853

4. Holman RR, Paul SK, Bethel MA, Matthews DR, Neil HA (2008) 10-year follow-up of intensive glucose control in type 2 diabetes. N Engl J Med 359:1577-1589

5. Jansen HJ, Hendriks JC, de Galan BE, Penders G, Tack CJ, Vervoort G (2011) Contribution of change in glycosylated haemoglobin to insulinassociated weight gain: results of a longitudinal study in type 2 diabetic patients. Endocrine 39:190-197

6. Jansen HJ, Vervoort G, van der Graaf M, Tack CJ (2010) Pronounced weight gain in insulin-treated patients with type 2 diabetes mellitus is associated with an unfavourable cardiometabolic risk profile. Neth J Med 68:359-366

7. Holman RR, Thorne KI, Farmer AJ et al (2007) Addition of biphasic, prandial, or basal insulin to oral therapy in type 2 diabetes. N Engl J Med 357:1716-1730

8. Salle A, Ryan M, Guilloteau G, Bouhanick B, Berrut G, Ritz P (2005) 'Glucose control-related' and 'non-glucose control-related' effects of insulin on weight gain in newly insulin-treated type 2 diabetic patients. Br J Nutr 94:931-937

9. Holst JJ, Deacon CF, Vilsboll T, Krarup T, Madsbad S (2008) Glucagon-like peptide-1, glucose homeostasis and diabetes. Trends Mol Med 14:161-168

10. Marre M, Shaw J, Brandle M et al (2009) Liraglutide, a once-daily human GLP-1 analogue, added to a sulphonylurea over 26 weeks produces greater improvements in glycaemic and weight control compared with adding rosiglitazone or placebo in subjects with Type 2 diabetes (LEAD-1 SU). Diabet Med 26:268-278

11. Nauck M, Frid A, Hermansen K et al (2009) Efficacy and safety comparison of liraglutide, glimepiride, and placebo, all in combination with metformin, in type 2 diabetes: the LEAD (liraglutide effect and action in diabetes)-2 study. Diabetes Care 32:84-90

12. Garber A, Henry R, Ratner R et al (2009) Liraglutide versus glimepiride monotherapy for type 2 diabetes (LEAD-3 Mono): a randomised, 52-week, phase III, double-blind, parallel-treatment trial. Lancet 373:473-481

13. Zinman B, Gerich J, Buse JB et al (2009) Efficacy and safety of the human glucagon-like peptide- 1 analog liraglutide in combination with metformin and thiazolidinedione in patients with type 2 diabetes (LEAD-4 Met+TZD). Diabetes Care 32:1224-1230

14. Russell-Jones D, Vaag A, Schmitz O et al (2009) Liraglutide vs insulin glargine and placebo in combination with metformin and sulfonylurea therapy in type 2 diabetes mellitus (LEAD-5 met+SU): a randomised controlled trial. Diabetologia 52:2046-2055

15. Nauck MA, Kemmeries G, Holst JJ, Meier JJ (2011) Rapid tachyphylaxis of the glucagon-like peptide 1-induced deceleration of gastric emptying in humans. Diabetes 60:1561-1565

16. Arnolds S, Dellweg S, Clair J et al (2010) Further improvement in postprandial glucose control with addition of exenatide or sitagliptin to combination therapy with insulin glargine and metformin: a proofof-concept study. Diabetes Care 33:1509-1515

17. Buse JB, Bergenstal RM, Glass LC et al (2011) Use of twice-daily exenatide in basal insulin-treated patients with type 2 diabetes: a randomized, controlled trial. Ann Intern Med 154:103-112

18. Lane W, Weinrib S, Rappaport J (2011) The effect of liraglutide added to U-500 insulin in patients with type 2 diabetes and high insulin requirements. Diabetes Technol Ther 13:592-595

19. Lane W, Weinrib S, Rappaport J, Hale C (2014) The effect of addition of liraglutide to high-dose intensive insulin therapy: a randomized prospective trial. Diabetes Obes Metab. doi:10.1111/dom.12286

20. Levin PA, Mersey JH, Zhou S, Bromberger LA (2012) Clinical outcomes using long-term combination therapy with insulin glargine and exenatide in patients with type 2 diabetes mellitus. Endocr Pract Off J Am Coll Endocrinol Am Assoc Clin Endocrinol 18:17-25

21. Li CJ, Li J, Zhang QM et al (2012) Efficacy and safety comparison between liraglutide as add-on therapy to insulin and insulin doseincrease in Chinese subjects with poorly controlled type 2 diabetes and abdominal obesity. Cardiovasc Diabetol 11:142

22. Lind M, Jendle J, Torffvit O, Lager I (2012) Glucagon-like peptide 1 (GLP-1) analogue combined with insulin reduces HbA1c and weight with low risk of hypoglycemia and high treatment satisfaction. Prim Care Diabetes 6:41-46

23. Mathieu C, Rodbard HW, Cariou B et al (2014) A comparison of adding liraglutide versus a single daily dose of insulin aspart to insulin degludec in subjects with type 2 diabetes (BEGIN: VICTOZA ADD-ON). Diabetes Obes Metab. doi:10.1111/dom.12262

24. Nayak UA, Govindan J, Baskar V, Kalupahana D, Singh BM (2010) Exenatide therapy in insulin-treated type 2 diabetes and obesity. QJM 103:687-694

25. Riddle MC, Aronson R, Home P et al (2013) Adding once-daily lixisenatide for type 2 diabetes inadequately controlled by established basal insulin: a 24-week, randomized, placebo-controlled comparison (GetGoal-L). Diabetes Care 36:2489-2496

26. Riddle MC, Forst T, Aronson R et al (2013) Adding once-daily lixisenatide for type 2 diabetes inadequately controlled with newly initiated and continuously titrated basal insulin glargine: a 24-week, randomized, placebo-controlled study (GetGoal-Duo 1). Diabetes Care 36:2497-2503

27. Seino Y, Min KW, Niemoeller E, Takami A, EG-LAS Investigators (2012) Randomized, double-blind, placebo-controlled trial of the oncedaily GLP-1 receptor agonist lixisenatide in Asian patients with type 2 diabetes insufficiently controlled on basal insulin with or without a sulfonylurea (GetGoal-L-Asia). Diabetes Obes Metab 14:910-917

28. Sheffield CA, Kane MP, Busch RS, Bakst G, Abelseth JM, Hamilton RA (2008) Safety and efficacy of exenatide in combination with insulin in patients with type 2 diabetes mellitus. Endocr Pract Off J Am Coll Endocrinol Am Assoc Clin Endocrinol $14: 285-292$

29. Thong KY, Jose B, Sukumar N et al (2011) Safety, efficacy and tolerability of exenatide in combination with insulin in the Association of British Clinical Diabetologists nationwide exenatide audit. Diabetes Obes Metab 13:703-710

30. Viswanathan P, Chaudhuri A, Bhatia R, Al-Atrash F, Mohanty P, Dandona P (2007) Exenatide therapy in obese patients with type 2 diabetes mellitus treated with insulin. Endocr Pract Off J Am Coll Endocrinol Am Assoc Clin Endocrinol 13:444-450

31. Yoon NM, Cavaghan MK, Brunelle RL, Roach P (2009) Exenatide added to insulin therapy: a retrospective review of clinical practice over two years in an academic endocrinology outpatient setting. Clin Ther 31:1511-1523

32. Polonsky WH, Anderson BJ, Lohrer PA et al (1995) Assessment of diabetes-related distress. Diabetes Care 18:754-760

33. Beck AT, Ward CH, Mendelson M, Mock J, Erbaugh J (1961) An inventory for measuring depression. Arch Gen Psychiatry 4:561-571

34. St-Onge M, Mignault D, Allison DB, Rabasa-Lhoret R (2007) Evaluation of a portable device to measure daily energy expenditure in free-living adults. Am J Clin Nutr 85:742-749

35. Balena R, Hensley IE, Miller S, Barnett AH (2013) Combination therapy with GLP-1 receptor agonists and basal insulin: a systematic review of the literature. Diabetes Obes Metab 15:485-502

36. Donnelly JE, Blair SN, Jakicic JM et al (2009) American College of Sports Medicine Position Stand. Appropriate physical activity intervention strategies for weight loss and prevention of weight regain for adults. Med Sci Sports Exerc 41:459-471

37. Wing RR, Lang W, Wadden TA et al (2011) Benefits of modest weight loss in improving cardiovascular risk factors in overweight and obese individuals with type 2 diabetes. Diabetes Care 34:1481-1486 